\title{
Development of new volume reduction technique for natural cohesive soil ground by disturbing
}

\author{
Yoshio Mitarai $^{\text {i) }}$, Yosuke Tanaka ${ }^{\text {ii) }}$, Daisuke Kiuchi ${ }^{\text {iii) }}$ \& Kohta Nishida ${ }^{\text {iii) }}$ \\ i) Deputy General Manager, R \& D Center, TOA Corporation, 1-3, Anzen-cho, Tsurumi-Ku, Yokohama 230-0035, Japan. \\ ii) Senior Researcher, R \& D Center, TOA Corporation, 1-3, Anzen-cho, Tsurumi-Ku, Yokohama 230-0035, Japan. \\ iii) Researcher, R \& D Center, TOA Corporation, 1-3, Anzen-cho, Tsurumi-Ku, Yokohama 230-0035, Japan.
}

\begin{abstract}
This paper covers a development of volume reducing method for natural cohesive soil ground by disturbance, generated by mixing machinery as utilized for cement deep mixing method. This method is based on the basic knowledge that compressibility of natural clay will be changed by sample disturbance. This paper summarizes basic effect of compressibility of natural clay on artificial disturbance by a series of laboratory oedometer tests. Through the tests using undisturbed clay samples taken in Japan, effects of disturbance on compressibility is examined. Then, simple estimation of potential settlements due to ground disturbance by mixing machinery is studied using liquid limit of clay sample, as basic clay intrinsic parameter. In addition, effect of coefficient of consolidation due to the disturbance is confirmed to control the consolidation speed in subsequent soil improvement work by pre-fabricated vertical drain. Finally, some probable application of this proposed method is mentioned.
\end{abstract}

Keywords: volume reduction, disturbance, natural cohesive soil, compressibility, disposal site

\section{INTRODUCTION}

It is generally known that sample taken from natural cohesive soil ground will induces disturbance of the soil structure due to mechanical disturbance during sampling and sample preparation, with stress release. From past research, the degree of disturbance of a sample is considered to be reflected in strength characteristics (stress-strain curve, strain at failure, modulus of deformation, etc.) and consolidation characteristics (shape of void ratio-consolidation pressure curve, consolidation yield stress, reduction of coefficient of consolidation etc.), and methods to evaluate and compensate for disturbances have been proposed (Schemertman et. al. 1955, Ladd et. al. 1963 and Okumura 1973). Because it is difficult to eliminate such disturbances completely during sampling or disturbances during soil improvement work with vertical drain installation, and disturbances greatly affect design and execution, including prediction of consolidation settlement, stability analysis, etc., they are generally considered undesirable. However, in this research, the effect of disturbance was summarized in laboratory experiments with the aim of proposing a new technique for volume reduction of natural cohesive ground and expansion of the capacity of soil disposal sites by positively utilizing disturbance.

\section{MECHANISM OF VOLUME REDUCTION BY POSITIVE DISTURBANCE}

Figure 1 shows the general concept of the mechanism of volume reduction by positive disturbance (Mitarai et. al. $2013 \&$ 2014). The blue and green lines in the figure are the compression curves for "Undisturbed" and "100\% Disturbed", respectively. Regarding the behavior of the original ground, it is thought that settlement occurs after compression stress exceeds the consolidation yield stress, as shown by the black broken line.

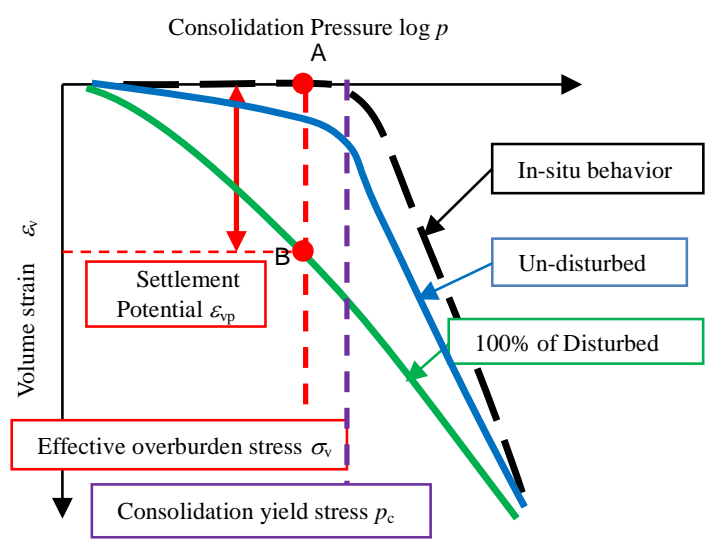

Fig. 1 Concept of mechanism of volume reduction by disturbance. 
If a specimen hypothetically having a certain effective overburden pressure (A) is disturbed, the compression curve of that specimen will perform settlement $\left(\varepsilon_{\mathrm{vp}}\right)$, as shown by the red arrow, due to a shift to the " $100 \%$ Disturbed" compression curve (B). This means that some amount of potential settlement, i.e., "settlement potential," exists if a volume-reduction-by-disturbance technique is applied to the ground.

\section{SPECIMENS AND EXPERIMENTAL METHOD}

\subsection{Specimen Used in Experiments}

The main physical properties of the specimens used in these experiments are shown in Table 1. A plasticity chart is shown in Fig. 2. All specimens were sampled with a stationary piston-type thin-wall sampler. After extraction, the specimens were coated with paraffin and stored in a constant temperature, constant humidity chamber (room temperature: $20 \pm 2^{\circ} \mathrm{C}$, room humidity: $95 \%$ or higher) to prevent drying.

Table 1 soil physical properties of clay

\begin{tabular}{cccccc}
\hline \multirow{2}{*}{ Sample } & \multirow{2}{*}{$\boldsymbol{\sigma}_{\mathbf{v}}^{\prime}$} & \multirow{2}{*}{$\boldsymbol{w}_{\mathbf{n}}$} & \multicolumn{4}{c}{ Atterberg limit } \\
\cline { 2 - 6 } & & & $\boldsymbol{w}_{\mathbf{L}}$ & $\boldsymbol{w}_{\mathbf{P}}$ & $\boldsymbol{I}_{\mathbf{P}}$ \\
\cline { 2 - 6 }$\left(\mathrm{kN} / \mathrm{m}^{2}\right)$ & $(\%)$ & $(\%)$ & $(\%)$ & $(\%)$ \\
\hline Saga Ariake A & 47.3 & 134 & 62 & 32 & 30 \\
\hline Saga Ariake B & 77.0 & 78 & 64 & 34 & 30 \\
\hline Tokyo Bay A & 224.2 & 88 & 103 & 45 & 58 \\
\hline Tokyo Bay B & 257.3 & 43 & 41 & 20 & 21 \\
\hline Tokyo Bay C & 270.0 & 38 & 31 & 23 & 8 \\
\hline Kobe & 35.2 & 101 & 106 & 40 & 66 \\
\hline Osaka bay A & 34.2 & 110 & 120 & 34 & 86 \\
\hline Osaka bay B & 95.3 & 49 & 57 & 24 & 33 \\
\hline
\end{tabular}

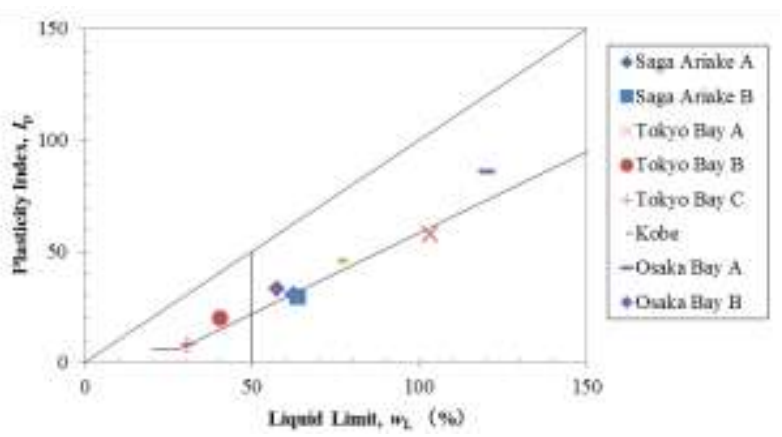

Fig. 2. Plasticity chart of clay samples used in this study.

\subsection{Experimental Method}

Two types of consolidation tests were adopted. One is standard step loading test (STD) in accordance with JIS A 1217, other is constant strain rate consolidation test (CRS) in accordance with JIS A 1227. During CRS test, continuous compression curve and coefficient of consolidation $c_{\mathrm{v}}$ can be obtained quickly. Then some samples are subjected to CRS to obtain continuous compression curve and $c_{\mathrm{v}}$. Others are subjected to STD to examine the effect of consolidation curve on disturbance. The strain rate is $0.02 \% / \mathrm{min}$ in CRS. The test method used with each sample is shown in Table 4.

The specimen preparation method and specimen conditions are shown in Fig. 3 and Table 2, respectively. "Undisturbed" specimens were prepared by extracting the middle $30 \mathrm{~mm}$ from the specimen height of approximately $100 \mathrm{~mm}$, and inserting the specimen in a consolidation ring. "100\% Disturbed" specimens were prepared by sampling the $30 \mathrm{~mm}$ section above the "Undisturbed" specimen, performing complete remolding to eliminate variations in water content, and packing a sample of the same weight as the "Undisturbed" specimen in a consolidation ring. For "50\% disturbance" and 75\% disturbance", the $30 \mathrm{~mm}$ section under the "Undisturbed" specimen was sampled, and complete remolding was performed in the same manner as with the " $100 \%$ disturbed" specimens. Dice of specimens with a size of 3-5 mm square were then cut out with a cutter, mixed uniformly at the mass ratios shown in Table 2, and packed in consolidation rings (see bottom of Fig. 3).

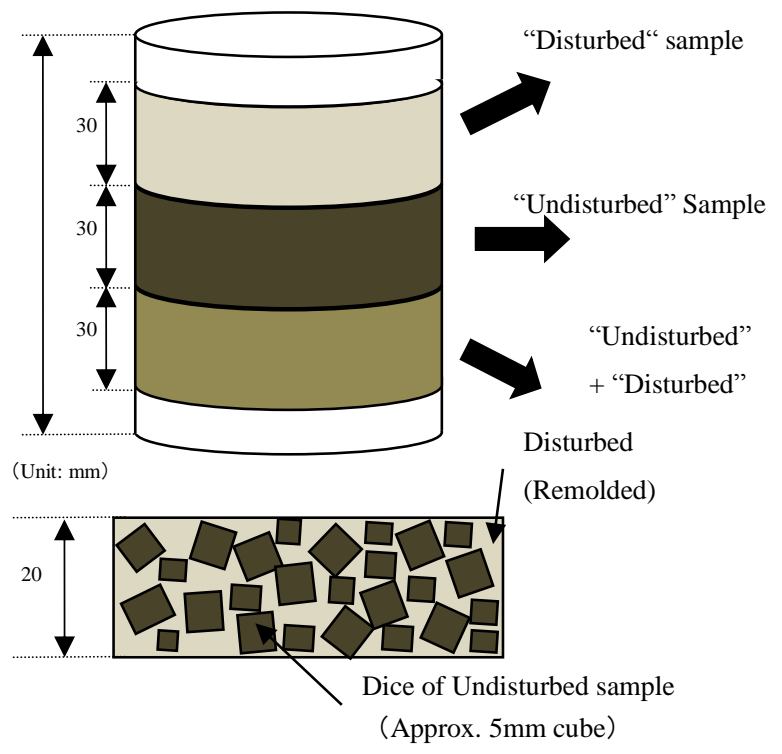

Fig. 3. Specimen preparation method.

Table 2. Mixing portion of Undisturbed and Disturbed sample.

\begin{tabular}{ccc}
\hline Case & Undisturbed sample & Remolded sample \\
\hline Undisturbed & $100 \%$ & $0 \%$ \\
\hline $50 \%$ of disturbed & $50 \%$ & $50 \%$ \\
\hline $75 \%$ of disturbed & $25 \%$ & $75 \%$ \\
\hline $100 \%$ of disturbed & $0 \%$ & $100 \%$ \\
\hline
\end{tabular}

\section{EXPERIMENTAL RESULTS}

\subsection{Effect of Degree of Disturbance on Results}

Figure 4 shows the relationship between the volumetric strain $\left(\varepsilon_{\mathrm{V}}\right)$ and consolidation pressure $(p)$ of Osaka Bay A and B from STD. As reported in past 
research, consolidation yield stress $\left(p_{\mathrm{c}}\right)$ decreases as a result of disturbance, and the form of the curve becomes gentle. It is noted that $50 \%$ and $75 \%$ disturbed sample is similar to that of $100 \%$ disturbed sample. The reason is due to stress concentrations are generated in the mixture of disturbed and undisturbed sample. Once stress concentration is generated, shear deformation is generated due to high stress occurs preferentially in the dice of undisturbed sample. As a result, the material approaches the remolded condition as $100 \%$ disturbed sample. Table 3 summarizes the volumetric strain when the specimens were loaded with the same effective overburden pressure $\left(\sigma_{\mathrm{v}}{ }^{\prime}\right)$ as in the original in-situ condition. From the table, it is noted that the volumetric strain more than $50 \%$ disturbed sample is more than $80 \%$ of that of $100 \%$ disturbed sample. (For example, in the case of Osaka Bay A, 10.0/13.3 = 0.81.)
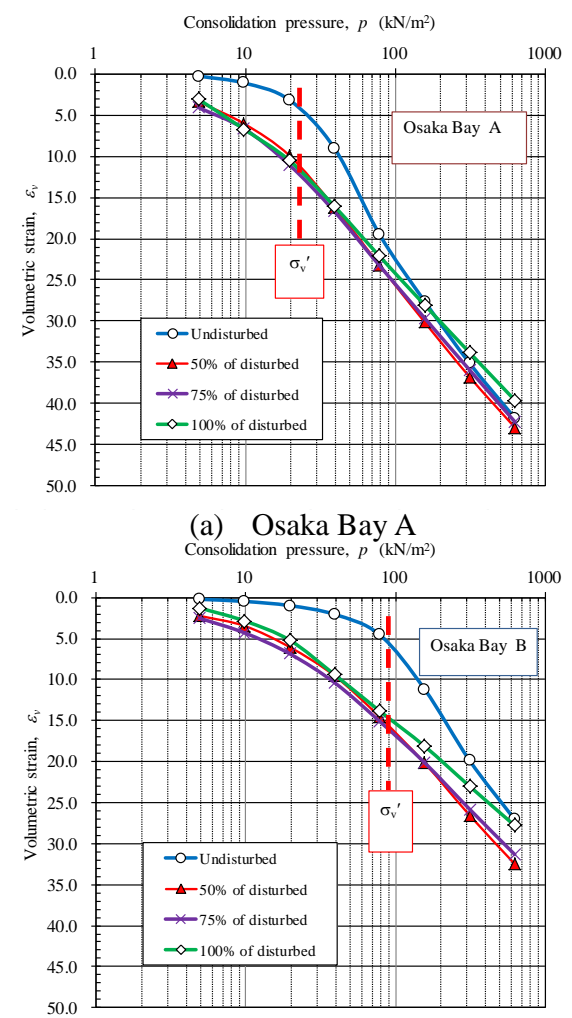

(b) Osaka Bay B

Fig. 4. Relationship of $\varepsilon_{\mathrm{v}}$ and $p$.

Table 3. Volumetric strain under effective overburden pressure.

\begin{tabular}{|c|c|c|c|}
\hline \multicolumn{2}{|r|}{ Sample } & \multirow{2}{*}{$\frac{\text { Osaka Bay A }}{34.2}$} & \multirow{2}{*}{$\begin{array}{c}\text { Osaka Bay B } \\
91.5\end{array}$} \\
\hline & $\sigma_{\mathrm{v}}^{\prime} \quad\left(\mathrm{kN} / \mathrm{m}^{2}\right)$ & & \\
\hline \multirow{4}{*}{$\begin{array}{c}\mathcal{E}_{\mathrm{v}} \\
\text { at } \sigma_{\mathrm{v}}{ }^{\prime} \\
(\%)\end{array}$} & Undisturbed & 4.2 & 5.6 \\
\hline & $50 \%$ of disturbed & 10.8 & 15.5 \\
\hline & $75 \%$ of disturbed & 11.9 & 15.9 \\
\hline & $100 \%$ of disturbed & 13.3 & 14.6 \\
\hline
\end{tabular}

\subsection{Influence of Physical Properties on Volume-} Reduction-by-Disturbance Effects

Figures 5 and 6 show the compression curves (volumetric strain and consolidation stress) obtained from all consolidation tests for the cases of "Undisturbed" sample and " $100 \%$ disturbed" sample. With all specimens, the compression curve changes and compressibility increases as a result of disturbance. Table 4 shows the results when the "settlement potential" $\varepsilon_{\mathrm{vp}}$ of the " $100 \%$ disturbance" specimens under the in-situ effective overburden pressure is read from Fig. 5. From these results, the volumetric strain of $100 \%$ disturbed sample tends to become larger as the yield point of the compression curve of the undisturbed specimens becomes clearer. The relationship between $\varepsilon_{\mathrm{vp}}$ and the liquid limit is arranged in Fig. 6. In this figure, a positive correlation between $\varepsilon_{\mathrm{vp}}$ and the $w_{\mathrm{L}}$ can be seen. Due to differences in the fine contents of the sample used here and other factors, it is not possible to draw a definitive line from the results presented in this paper alone. However, these results suggest that "settlement potential" becomes greater as the liquid limit increases.

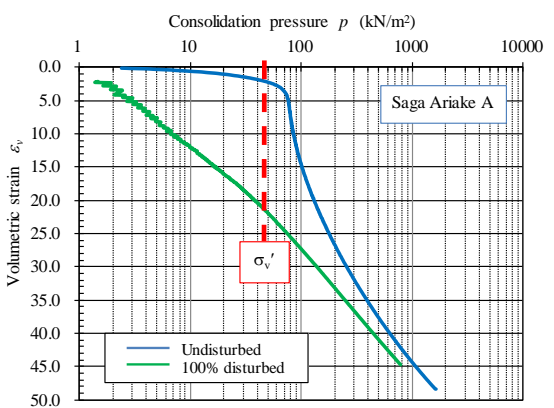

(a) Saga Ariake A

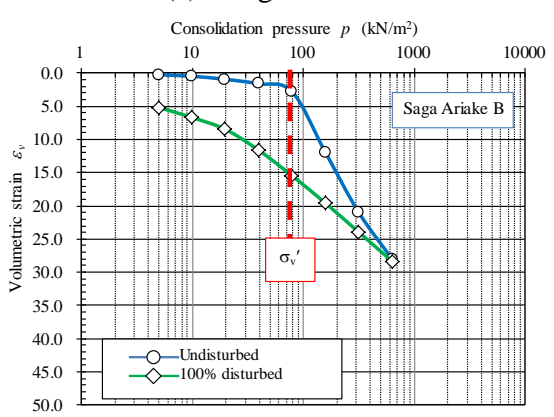

(b) Saga Ariake B

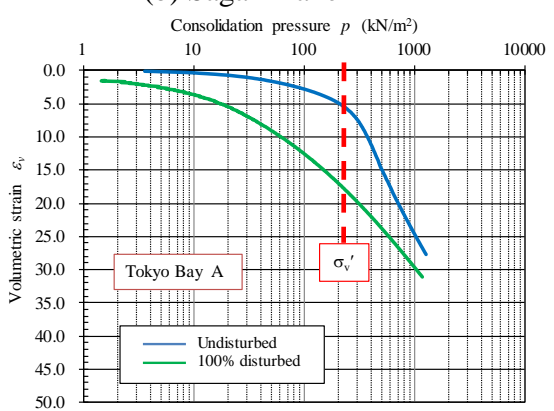

(c) Tokyo Bay A

Fig. $5 \varepsilon_{\mathrm{v}}-\log p$ relationship

(Saga Ariake A \& B, Tokyo Bay A) 


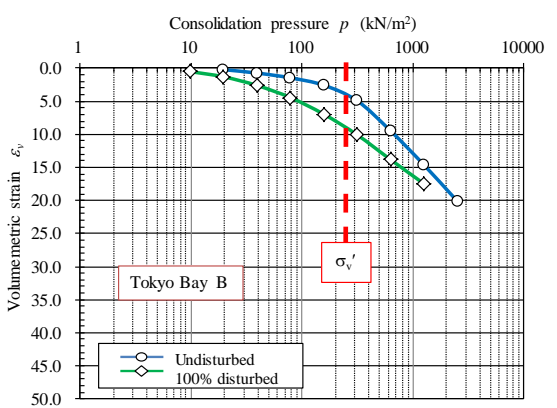

(d) Tokyo Bay B

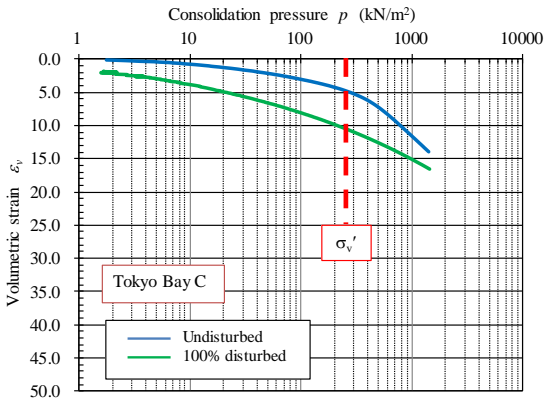

(e) Tokyo Bay C

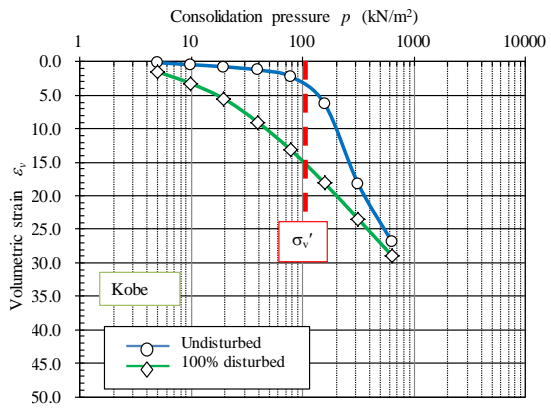

(f) Kobe

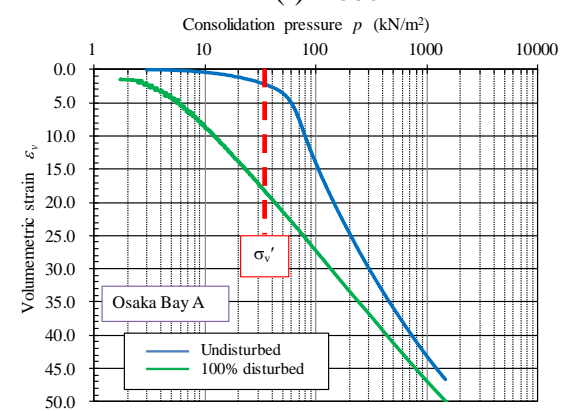

(g) Osaka Bay A

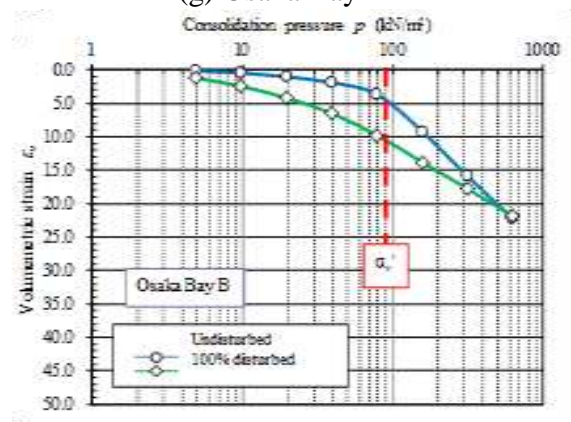

(h) Osaka Bay B

Fig. $6 \varepsilon_{\mathrm{v}}-\log p$ relationship

(Tokyo Bay B \& C, Kobe, Osaka Bay A \& B )
Table 4 Results of consolidation tests

\begin{tabular}{ccccc}
\hline No. & Sample & $\begin{array}{c}\text { Testing } \\
\text { Method }\end{array}$ & $\begin{array}{c}\boldsymbol{w}_{\mathrm{L}} \\
(\boldsymbol{\%})\end{array}$ & $\begin{array}{c}\text { Volume strain at } \\
\text { in-situ stress level } \\
\left(\boldsymbol{\boldsymbol { \varepsilon } _ { \mathrm { V } }}\right)\end{array}$ \\
\hline 1 & Saga Ariake A & CRS & 62 & 21.6 \\
\hline 2 & Saga Ariake & STD & 64 & 15.3 \\
\hline 3 & Tokyo Bay A & CRS & 103 & 18.2 \\
\hline 4 & Tokyo Bay B & STD & 41 & 8.0 \\
\hline 5 & Tokyo Bay C & CRS & 31 & 10.7 \\
\hline 6 & Kobe & STD & 76 & 15.0 \\
\hline 7 & Osaka Bay A & CRS & 120 & 17.0 \\
\hline 8 & Osaka Bay B & STD & 57 & 10.6 \\
\hline
\end{tabular}

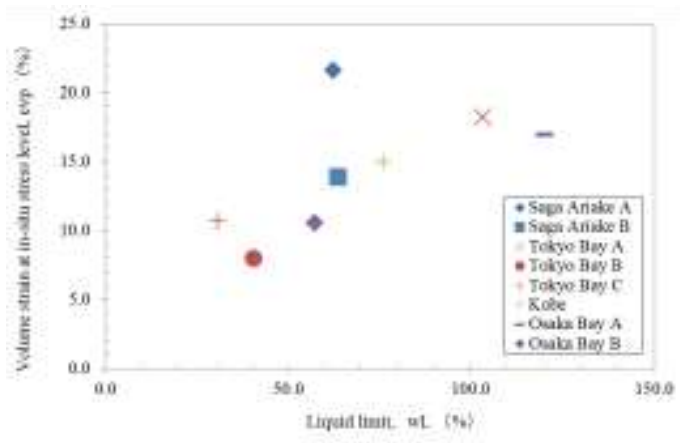

Fig. 7. $\varepsilon_{\mathrm{vp}}-w_{\mathrm{L}}$ relationship

\subsection{Influence of Disturbance on Coefficient of Consolidation}

Figures 8 and 9 show the relationship between the coefficient of consolidation and the mean consolidation pressure obtained from the consolidation tests of Osaka Bay A and B. The fact that the coefficient of consolidation decreases due to disturbance can be confirmed. In particular, in the case of "Undisturbed", the coefficient of consolidation decreases in the stress range of the over-consolidated region. This is considered to be due to a change in compressibility. Thus, in the volume-reduction-by-disturbance technique, it is necessary to determine the coefficient of consolidation by a consolidation test before design of the drain after disturbance.

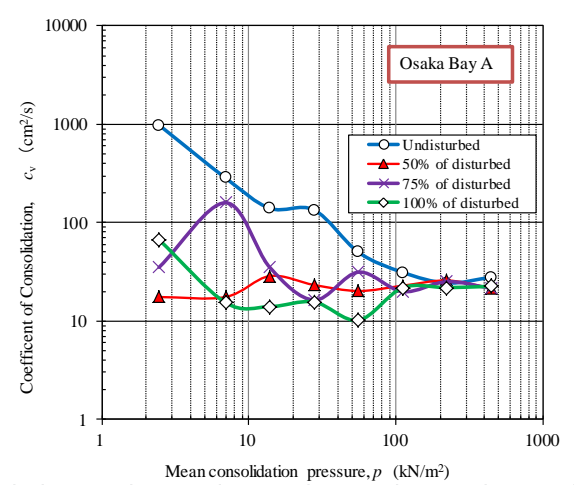

(a) Osaka Bay A

Fig. $8 \log c_{\mathrm{v}}-\log p$ relationship (Osaka Bay A) 


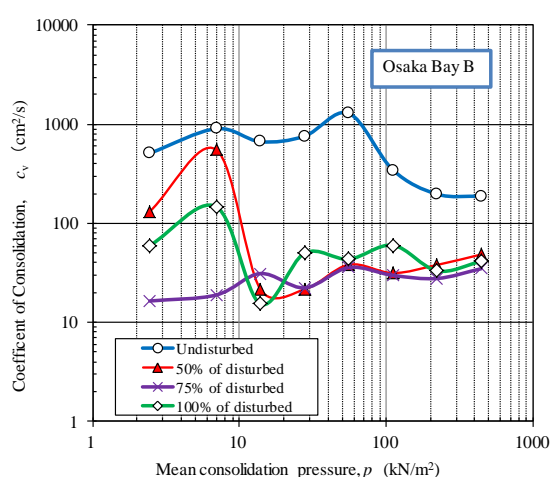

(b) Osaka Bay B

Fig. $9 \log c_{\mathrm{v}}-\log p$ relationship (Osaka Bay B)

\section{PROPOSALS FOR APPLICATION AT ACTUAL SITES}

The following are possible applications of the volume-reduction-by-disturbance technique at actual sites.

(1) Securing capacity and volume reduction at soil disposal sites (e.g., at newly-constructed sites and at sites where landfill has been completed)

(2) Securing water area of reservoirs, lakes, and marshes, etc.

(3) Containment of contaminated soil

(4) Reduction of excavation and dredging soil and soil disposal (including reduction to zero)

Possible applications are required for all locations including cohesive soil layer in the ground without soil improvement work such as vertical drain. Regarding (1) and (4), in particular, due to the shortage of soil disposal sites in recent years, there is a strong need to increase the capacity of existing soil disposal sites in cases where new construction would be difficult. Where (3) is concerned, when the reclaimed ground at existing landfill sites contains pollutants, the amount of contaminated soil generated by construction work and the amount of soil requiring disposal can be greatly reduced by promoting settlement of the natural sedimentary ground where this is possible.

In implementation of the proposed technique, various methods of disturbing the ground are applicable. However, probable candidate is a method using the equipment of the deep mixing method, in which a stabilizer is mixed with the soil while agitating the ground with an impeller. As the necessary mixing time, including rod installation and withdrawal time, for forming a homogeneous stabilized soil-cement column has already been determined, this is a proven method with a uniform mixing capacity.

\section{CONCLUSIONS}

As mentioned, the effects of disturbance on soils in laboratory tests and disturbance of the ground during construction were frequently considered to be negative as of now. On the other hand, the proposed technique is the result of, so to speak, a reversal in thinking, in that the effects of positive disturbance are actively utilized. In this study, a series of consolidation tests were carried out using specimens with different degrees of disturbance, and the influence of differences in the degree of disturbance and the physical properties of the specimens on compressibility was studied. The following knowledge was obtained.

(1) As reported in past study, $p_{\mathrm{c}}$ decreases as a result of disturbance, and the shape of the compression curve also changes greatly. When disturbance is applied, large volumetric strain occurs at the same $p$ in comparison with the case of "undisturbed".

(2) With 50\% "disturbed", a compression curve similar to that of $100 \%$ disturbed sample was obtained. This means that $100 \%$ disturbance of the ground is not required in actual mixing perfectly, and a sufficient volume reduction effect can be obtained with more than $50 \%$ of disturbance.

(3) "Settlement potential" shows a tendency to increase as the liquid limit increases.

\section{REFERENCES}

1) Schemertman, J.H. (1955): The Undisturbed Consolidation Behavior of Clay, Trans. ASCE, Vol. 120, pp. 1201 1233.

2) Ladd, C.C. and Lambe, T.W.(1963): The strength of "Undisturbed" Clay Determined from Undrained Tests, ASTM STP-361, Laboratory Shear Testing of Soils, pp. 342-371.

3) Okumura, T. (1973): Studies on the disturbance of clay soils and improvement of their sampling techniques, Technical Note of the Port and Harbour Research Institute Ministry of Transport, No. 193 (in Japanese).

4) Mitarai, Y., Tanaka, Y. and Nishida, K. (2013): Influence of disturbance on consolidation properties of natural cohesive soil and its positive utilization, Proceedings of $68^{\text {th }} J S C E$ annual conference, Div. III, 419-420, (in Japanese).

5) Mitarai, Y., Tanaka, Y., Kiuchi, D. and Nishida, K. (2014): Newly Technique for Reduction of Cohesive Ground by Positive Disturbing, Geotechnical Engineering Magazine, 62(5), 28-29 (in Japanese). 